\title{
A Comparative Evaluation of the Effectiveness of Saline, Chlorhexidine and Ozone Irrigating Solutions on Microorganisms in the Root Canal - An In Vivo Study
}

\author{
Alan Winston David ${ }^{1}$, Sarvepalli Venkata Satish ${ }^{2 *}$, Sudhir Dole ${ }^{3}$, \\ Suresh Kumar Kovvuru ${ }^{4}$ and Basavana Gowda ${ }^{5}$ \\ ${ }^{1}$ Postgraduate Student, Department of Conservative Dentistry and Endodontics, \\ Navodaya Dental College, Navodaya Nagar, Raichur, India \\ ${ }^{2}$ Professor and Head of the Department, Department of Conservative Dentistry and \\ Endodontics, Navodaya Dental College, Navodaya Nagar, Raichur, India \\ ${ }^{3}$ Consultant Dentist for Ozone Therapy and Trainer, Mumbai, India \\ ${ }^{4}$ Professor, Department of Conservative Dentistry and Endodontics, Navodaya Dental \\ College, Navodaya Nagar, Raichur, India \\ ${ }^{5}$ Reader, Department of Conservative Dentistry and Endodontics, Navodaya Dental \\ College, Navodaya Nagar, Raichur, India \\ *Corresponding Author: Sarvepalli Venkata Satish, Professor and Head of the \\ Department, Department of Conservative Dentistry and Endodontics, Navodaya \\ Dental College, Navodaya Nagar, Raichur, India.
}

Received: August 25, 2020

Published: September 26, 2020

(C) All rights are reserved by Sarvepalli

Venkata Satish., et al.

\begin{abstract}
Background: To evaluate the effectiveness of normal saline, 2\% Chlorhexidine solution and Ozone oil on microorganisms in the root canal.

Materials and Methods: This study was carried out on 45 patients, out of which 60 anterior fractured teeth were selected which are asymptomatic, non-vital and necrotic in nature. Teeth were randomly divided into three groups of 20 each depending upon the type of irrigants used i.e. Saline, Chlorhexidine and Ozone. After access opening, two microbial samples were taken from each tooth: a) Pre- irrigation i.e. sample after pulp extirpation and before irrigation, b) Post-irrigation i.e. sample after irrigation, which were stored in sterile containers and immediately transferred to microbiological laboratory for incubation aerobically at $37^{\circ} \mathrm{C}$ for 24 hours. Then, the samples were streaked on blood agar culture media and incubated for 48 hours. After 48 hours, the colony forming units were counted using a colony counter. Statistical analysis was carried out using Kruskal-Wallis test, Wilcoxson signed rank test and MannWhitney test.

Results: On intra group comparison, highly significant differences in the colony forming units were found between pre- and postirrigated samples for all the three irrigants used i.e. saline, chlorhexidine and ozone. On inter group comparison, statistical difference was found between saline (group 1) and chlorhexidine (group 2), saline (group 1) and Ozone oil (group 3), chlorhexidine (group 2) and Ozone oil (group 3).

Conclusion: The result of this study shows that Ozone oil irrigating solution can be used as an irrigating solution and its antibacterial action is effective when it is compared with $2 \%$ chlorhexidine and saline.
\end{abstract}

Keywords: Saline; Chlorhexidine; Ozone Oil; Non-Vital Teeth

Citation: Sarvepalli Venkata Satish., et al. "A Comparative Evaluation of the Effectiveness of Saline, Chlorhexidine and Ozone Irrigating Solutions on Microorganisms in the Root Canal - An In Vivo Study". Acta Scientific Dental Sciences 4.10 (2020): 76-81. 


\section{Introduction}

The major role of micro-organisms in the initiation and progression of lesions like apical and peri-radicular has been very well established. An infected root canal caused either due to caries exposure or trauma cannot be removed by using the host defence mechanisms alone or in combination with systemic antibiotic therapy. Therefore, there arises a need to supply therapy in concise way along with preparation which has been referred to as chemo-mechanical preparation: as both components are necessary for successful procedural outcomes and are generally performed together [1]. According to literature, innumerable compounds have been proposed as root canal irrigants. Chlorhexidine is considered as an efficient broad-spectrum antiseptic and it has low toxicity, substantivity and antibacterial properties against gram negative and gram-positive bacteria as well as yeast. Thus, it has been used widely in the dentistry [2].

Ozone is a triatomic endothermic and thermodynamically highly instable oxygen compound. Gaseous and aqueous form of ozone was shown to be reliable and powerful antimicrobial agent against fungi, viruses, bacteria and protozoa. Ozone was widely appreciated as oxidant potential of which induces the damage of cell walls and cytoplasmic membranes of bacteria and fungi. On its way, ozone attacks glycolipids, glycoproteins and other amino acids. It inhibits and clogs the enzymatic control system of the cell. This effect will enhance the membrane permeability which is the key element of cell viability leading to immediate functional cessation. At this point ozone particles can promptly enter the cell and cause the microorganism to kick the bucket [3].

Ozone can be used in various forms for the treatment of endodontic conditions such as Ozonated water, gaseous ozone and Ozonized oil.

Even though, there are many studies available regarding the use of ozonated water and gaseous ozone, there is no study exist in the literature regarding the use and efficacy of ozonized oil as an endodontic irrigant, however it was used in various medical and dental fields.

\section{Aim of the Study}

Thus, the aim of the study is to evaluate the effectiveness of normal saline, 2\% Chlorhexidine and Ozone oil as irrigating solutions on microorganisms in the root canal.

\section{Materials and Methods}

This study was conducted in the Department of Conservative Dentistry and Endodontics, Navodaya Dental College, Raichur. Patients were diagnosed clinically of age 14 years and above irrespective of sex and socio-economic status and informed consent was taken. A fractured single rooted asymptomatic non-vital teeth with healthy and no previous history of antibiotic treatment during the past 3 months were included in the study. Teeth with intraoral or extra oral sinus, presence of abscess/soft tissue swelling were excluded from the study [1].

Total number of patients were 45, among them 60 teeth were selected and randomly divided into three groups of 20 teeth each, depending upon the type of irrigant [1]:

- Group 1- Saline (Pentagon Labs Ltd, Dewas, India).

- Group 2- 2\% Chlorhexidine solution (Indoco remedies Ltd., Aurangabad, India).

- $\quad$ Group 3- Ozone oil (ADC Inc Dentozone, India).

For each tooth, two samples were collected in order to evaluate the level of total colony forming units [4]:

- $\quad$ Sample A- Pre-irrigation i.e. before irrigation and just after pulp extirpation.

- $\quad$ Sample B- Post-irrigation i.e. after irrigation.

\section{Specimen collection procedure}

The procedure was performed under local anaesthesia with $2 \%$ lignocaine hydrochloride containing adrenaline at a concentration of 1:2,00,000. Isolation of tooth was done under rubber dam and disinfected using povidone iodine solution. Access cavity preparation was performed by using sterile bur. After initial entry to the pulp space, the root canal was minimally instrumented upto \#20 $\mathrm{K}$ file and the pulp was extirpated with sterile broach without using any irrigant. A sterile paper point was introduced into the full length of the canal and retained in position for 60 seconds for microbial sampling [5]. Sample A was obtained with a paper point's length and diameter compatible with that of the root canal.

The paper point was removed from the root canal and was immediately placed in a sterile container containing peptone water and transferred to microbiology laboratory [Raichur Institute of Medical Science, Raichur]. The canal was irrigated with the irrigant allotted to that particular group. The irrigant remained in contact within the canal for five minutes. Post-irrigation: Sample B was ob- 
tained in the similar manner as described earlier. Consequently, a sterile cotton pellet was placed at the canal entrance and the root canal was left empty and temporarily sealed with intermediate restorative material. All the microbiological samples that were collected were then microbiologically processed to determine the viable colony forming units [4].

\section{Microbiology procedure}

In the microbiology lab, all the samples were incubated in the incubator at $37^{\circ} \mathrm{C}$ for 24 hours. After 24 hours, each sample was inoculated on defibrinated blood agar with the help of sterile inoculating loop of $0.04 \mathrm{~mm}$ diameter. Individual plate was aerobically incubated at $37^{\circ} \mathrm{C}$ in the incubator. After 48 hours the growth was evaluated and the total colony forming units were counted using a colony counter. The count per ml was recorded and multiplied with the dilution factor. The organisms were counted as Colony Forming Units (CFU) per ml [4].

Formula applied:

$$
\text { No. of Colonies } \times \text { Dilution Factor }
$$

$\mathrm{CFU}=$ Volume Inoculated
All the values of CFU were converted to $\mathrm{LOG}_{10}{ }^{10}$ for the ease of comparison and were carried out using Microsoft excel sheet (2010) [4].

\section{Statistical analysis}

Statistical analysis was carried out using SPSS version 17 for windows program. Kruskal-Wallis Test was used to compare the mean CFU of Group 1 (saline), Group 2 (chlorhexidine solution), Group 3 (Ozone) of Sample A and Sample B. For intra group comparison of mean CFU of Sample A (pre-irrigation) and Sample B (post-irrigation), Wilcoxson signed rank test was used. MannWhitney test was used for intergroup comparison of mean CFU.

\section{Results}

Table 1 shows the descriptive statistics of three irrigants pertaining to pre- and post-irrigation colony forming unit values i.e. mean $\mathrm{LOG}_{10}{ }^{10}$ (CFU) and Std. Deviation of Group 1 - Saline, Group 2 - Chlorhexidine solution and Group 3 - Ozone oil. Results suggested that statistically significant difference was observed in the mean $\mathrm{LOG}_{10}{ }^{10}(\mathrm{CFU})$ between the three groups in post-irrigation sample (Table 2).

\begin{tabular}{|c|c|c|c|c|c|c|}
\hline & & $\mathbf{N}$ & Minimum & Maximum & Mean & Std. Deviation \\
\cline { 2 - 7 } Pre irrigation & Group 1 & 20 & 4.1986 & 5.9784 & 4.952095 & .5390202 \\
\cline { 2 - 7 } & Group 2 & 20 & 4.1278 & 5.9873 & 4.816095 & .5620529 \\
\cline { 2 - 7 } & Group 3 & 20 & 4.1597 & 5.3546 & 4.660170 & .3699713 \\
\hline \multirow{4}{*}{ Post irrigation } & & $\mathbf{N}$ & Minimum & Maximum & Mean & Std. Deviation \\
\cline { 2 - 7 } & Group 1 & 20 & 4.0045 & 4.9865 & 4.384190 & .2477160 \\
\cline { 2 - 7 } & Group 2 & 20 & 2.3646 & 4.9875 & 3.381220 & .6940252 \\
\cline { 2 - 7 } & Group 3 & 20 & 1.1356 & 1.9846 & 1.577745 & .2654525 \\
\hline
\end{tabular}

Table 1: Descriptive statistics of the colony forming units table pre-irrigation and post irrigation.

\begin{tabular}{|l|c|c|}
\hline & Kruskal-Wallis & P value \\
\hline Pre & 2.64 & 0.267 \\
\hline Post & 48.40 & $0.00^{*}$ \\
\hline *Significant \\
$\begin{array}{l}\text { Pre scores showed no significant difference } \\
\text { among the groups (p }=0.267) \text { whereas there was } \\
\text { a significant difference seen with post scores }\end{array}$ \\
\hline
\end{tabular}

The intra group comparison suggested statistically significant difference between the samples of Group 1 (Saline), Group 2 (Chlorhexidine solution) and Group 3 (Ozone) (Table 3). The inter group comparison showed statistically significant result between Group 1 and Group 2, Group 1 and Group 3, Group 2 and Group 3 (Table 4 and graph 1).

Table 2: Comparison of the pre and post values among the groups using Kruskal-Wallis. 
A Comparative Evaluation of the Effectiveness of Saline, Chlorhexidine and Ozone Irrigating Solutions on Microorganisms in the Root Canal - An In Vivo Study

\begin{tabular}{|c|c|c|c|c|c|c|c|c|}
\hline & & Minimum & Maximum & Mean & S.D & Median & Mean diff & $P$ value \\
\hline \multirow[t]{2}{*}{ Group 1} & Pre & 4.1986 & 5.9784 & 4.9520 & .53902 & 4.9723 & \multirow[t]{2}{*}{0.5679} & \multirow[t]{2}{*}{$0.00^{*}$} \\
\hline & Post & 4.0045 & 4.9865 & 4.3841 & .24771 & 4.3475 & & \\
\hline \multirow[t]{2}{*}{ Group 2} & Pre & 4.1278 & 5.9873 & 4.8160 & .56205 & 4.7458 & \multirow[t]{2}{*}{1.434} & \multirow[t]{2}{*}{$0.00^{*}$} \\
\hline & Post & 2.3646 & 4.9875 & 3.3812 & .69402 & 3.4369 & & \\
\hline \multirow[t]{2}{*}{ Group 3} & Pre & 4.1597 & 5.3546 & 4.6601 & .36997 & 4.5672 & \multirow[t]{2}{*}{3.082} & \multirow[t]{2}{*}{$0.00^{*}$} \\
\hline & Post & 1.1356 & 1.9846 & 1.5777 & .26545 & 1.4759 & & \\
\hline \multicolumn{9}{|c|}{ *Significant } \\
\hline \multicolumn{9}{|c|}{$\begin{array}{l}\text { Wilcoxon test is applied to compare the statistical difference within the group at different time intervals. } \\
\text { Statistically significant difference was seen with pre and post scores with respect to all the groups }(p=0.00)\end{array}$} \\
\hline
\end{tabular}

Table 3: Comparison of the pre and post CFU within the groups using Wilcoxon sign test.

\begin{tabular}{|l|c|c|}
\hline & U value & P value \\
\hline Group 1 v/s Group 2 & -4.49 & $0.00^{*}$ \\
\hline Group 1 v/s Group 3 & -5.41 & $0.00^{*}$ \\
\hline Group 2 v/s Group 3 & -5.41 & $0.00^{*}$ \\
\hline \multicolumn{2}{|c|}{ * P value set significant at 0.05/3 = 0.016 } \\
Post-hoc Mann Whitney test was applied to compare the post \\
$\begin{array}{c}\text { score difference between the groups. There was a statistically } \\
\text { significant difference between group1 and group 2; group 1 } \\
\text { and group 3; group 2 and group 3 (p = 0.00). }\end{array}$
\end{tabular}

Table 4: Comparison of the post CFU scores between the groups using Post-Hoc Mann-Whitney.

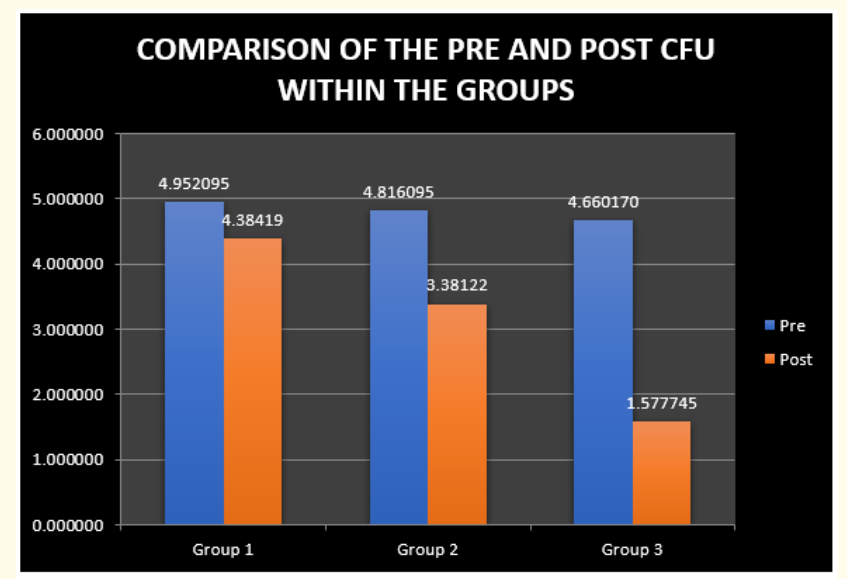

Graph 1: Mean comparison of $\mathrm{LOG}_{10}{ }^{10}(\mathrm{CFU})$ of sample A (Pre-irrigation) and sample B (post-irrigation) for Group 1 (Saline), Group 2 (Chlorhexidine) and Group 3 (Ozone).

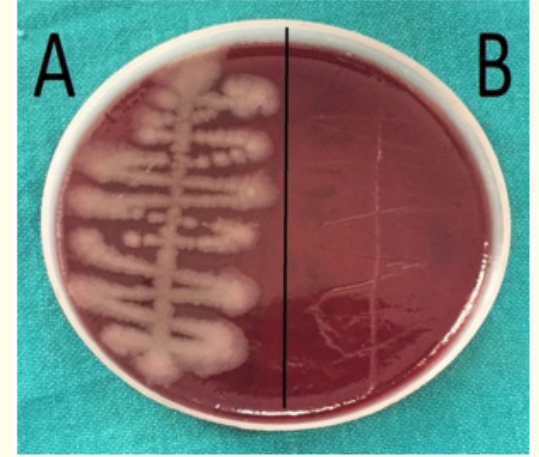

Figure 1: "A" Pre irrigation and "B" post irrigation streak of ozone oil irrigation solution.

\section{Discussion}

Root canal disinfection is one of the important steps in the root canal treatment. Root canal irrigants have been researched often for innovative means to end up with an ideal irrigating solution.

Cvek M., et al. showed that flushing with normal saline had poor antibacterial action [6]. In a classic study, which was conducted by Byström and Sundqvist studied the existence of bacteria in single-rooted teeth in presence of peri-apical lesions, which were irrigated with saline solution during instrumentation [7]. Mechanical-manual instrumentation reduced the number of bacteria from canal. Neutral irrigant such as saline is not able to adequately debride canals to be free of pulp tissue debris or bacteria [8]. Thus, normal saline has been used as a control in this study. 
Ozone therapy was used in medical practice for various modalities [9]. Ozone water, ozone gas, ozonized sunflower or olive oil are the different forms of ozone which can be used in dentistry.

Treatment modalities of ozone therapy includes [10]:

- $\quad$ Endodontic treatment

- Tooth extraction

- $\quad$ Biofilm purging

- Periodontal pocket disinfection and osseous disinfection

- $\quad$ Prevention of dental caries

- Tooth sensitivity

- Temporomandibular joint treatment

- Gingival recession

- Pain control

- Infection control

- Accelerating of wound healing

- Tissue regeneration

- Controlling halitosis

- Remineralization of tooth surface

- Tooth bleaching.

It shows the potential actions like anti-inflammatory, antimicrobial (bactericidal, viricidal and fungicidal), immunostimulatory, antihypoxic and detoxicating, biosynthetic (activation of the metabolism of carbohydrates, proteins, lipids) bioenergetics, hemostatic etc [11].

In a study conducted by Siqueira., et al. on evaluation of antibacterial activities of ozonized oil and calcium hydroxide paste against bacterial species and they concluded that ozonized oil is effective against evaluated bacterial species than calcium hydroxide paste. Hydrolysis action of ozonized oil can give rise to hydrogen peroxide, aldehydes, and ketones. Hydrogen peroxide acts as an oxidant which attacks essential cellular components such as lipids, proteins, and nucleic acids. As a consequence, it can induce disruption of the integrity of the bacterial cytoplasmic membrane, oxidation of enzymes and damage to DNA. Aldehydes have strong antibacterial activity by inducing the formation of cross-bonds in proteins with subsequent inhibition of several enzymes involved in the bacterial metabolism and also act as an alkylating effect on carboxyl, sulfhydryl and hydroxyl groups present in nucleic acids and/or proteins. Unsaturated fatty acids in the oil have antimicrobial effects in the cytoplasmic membrane such as inducing lethal structural perturbations, disruption of the membrane integrity and release of intracellular constituent. Therefore, the ozonized oil has the potential to be used as an intracanal medication. Ozone is a powerful, easy to use, cost effective and quick in action. Ozone is much stronger than chlorine and acts 3,000 times faster without producing harmful decomposition products $[3,12]$.

Vianna., et al. collected samples with paper points pooled in a sterile tube inoculated sample on media and incubated for both aerobically $\left(37^{\circ} \mathrm{C}\right.$, air) for 24 and 48 hours and anaerobically $37^{\circ} \mathrm{C}$ for 7 days [14]. In the present study the antimicrobial activity was evaluated by aerobically incubating the microbiological samples for 48 hours. Pre-irrigation and post-irrigation samples were obtained to evaluate the role of irrigant in reducing the microbial flora present in the root canal.

Sabharwal., et al. demonstrated in a similar study where 88 teeth were divided into four groups of irrigating solution. One sample was recorded before irrigation and another sample was recorded post-irrigation. Where in methodology main action of irrigation was by flushing the root canal, post extirpation of pulp and establishing antimicrobial environment against the microbes [4]. The collected microbiological samples were incubated aerobically at $37^{\circ} \mathrm{C}$ for 24 hours and inoculated with inoculating loop of 0.04 $\mathrm{mm}$ diameter on blood agar media. Later, streaked pre and postirrigation samples on separate chocolate agar using a calibration loop of $0.04 \mathrm{~mm}$ diameter that holds $0.01 \mathrm{ml}$ media. The plate was incubated an aerobically at $37^{\circ} \mathrm{C}$ for 72 hours and the numbers of colonies were counted.

This study was performed for evaluating the antimicrobial effect of three irrigants namely normal saline, $2 \%$ chlorhexidine solution and ozone oil by aerobic culture method. On intra group comparison all three irrigants showed statistically very high reduction in microbial load. Where normal saline has the ability to remove debris from the root canal rather than having antimicrobial property. This is in comparison with the findings of Akpata in 1976 who observed a significant reduction in the total viable count of microorganisms using saline as the irrigant [13]. Whereas there is a statistically significant difference between chlorhexidine and ozonated oil which is in accordance with the study conducted by Montevecchi., et al. where ozonated oil is more effective than chlorhexidine [15]. 


\section{Conclusion}

The ozone oil irrigating solution used in the present study may able to niche a suitable place for it in dentistry as it may provide complete antibacterial environment in the infected root canal. Based on the results of this it can be concluded that ozone oil irrigating solution has superior antibacterial activity with that of chlorhexidine solution in eliminating the aerobic microbial flora from infected root canals. Even though normal saline possesses no antibacterial property but was effective in reducing the microbial load due to its flushing action. As this study was not carried on individual microorganisms since the micro-flora of the root canal is mixed in nature. But the results obtained from individual micro-organisms may vary. Hence, this study emphasizes only the antibacterial effectiveness which has been evaluated by incubating sample aerobically, it could be further extended by evaluating the antibacterial efficacy against anaerobic micro-organisms as well as individual micro-organisms. Further studies are also recommended to evaluate the physiochemical properties of the ozone oil irrigating solution to improvise its efficacy in vivo.

\section{Bibliography}

1. Jain P., et al. "A Comparative Evaluation of the Effectiveness of Three Different Irrigating Solution on Microorganisms in the Root Canal: An In vivo Study". Journal of Clinical and Diagnostic Research 9.12 (2015): 39-42.

2. Haapasalo M., et al. "Eradication of endodontic infection by instrumentation and irrigation solutions". Endodontic Topics 10.1 (2005): 77-102.

3. Monika T., et al. "Ozone in Conservative Dentistry and Endodontics: A Review". International Journal of Clinical Preventive Dentistry 8.1 (2012): 29-35.

4. Sabharwal S., et al. "An In vivo study to compare anti microbial activity of triantibiotic paste, $2 \%$ chlorhexidine gel, and calcium hydroxide on microorganisms in the root canal of immature teeth". Journal of International Society of Preventive and Community Dentistry (2019): 263-268.

5. Orozco EI., et al. "Effect of passive ultrasonic activation on microorganisms in primary root canal infection: a randomized clinical trial". Journal of Applied Oral Science 28 (2020): 1-12.

6. Kudiyirickal MG and Ivancakova R. "Antimicrobial agents used in endodontic treatment". Acta Medica 51.1 (2008): 3-12.
7. Byström A and Sundqvist G. "Bacteriologic evaluation of the efficacy of mechanical root canal instrumentation in endodontic therapy". European Journal of Oral Sciences 89.4 (1981): 321-328.

8. Park E., et al. "Irrigation of the apical root canal". Endodontic Topics 27.1 (2012): 54-73.

9. Kumar T., et al. "Efficacy of ozonized olive oil in the management of oral lesions and conditions: A clinical trial". Contemporary Clinical Dentistry 7 (2016): 51-54.

10. Alpan AL and Bakar 0. "Ozone in Dentistry". Ozone in Nature and Practice 4 (2018): 57-75.

11. Komali G. "Ozone therapy a revolutionary noninvasive therapy in dentistry”. Scientific Reports 1.10 (2012): 1-3.

12. Silveira AMV., et al. "Periradicular repair after two-visit endodontic treatment using two different intracanal medications compared to single-visit endodontic treatment". Brazilian Dental Journal 18.4 (2007): 299-304.

13. Akpata ES. "Effects of endodontic procedure on the population viable microorganisms in the infected root canal". Journal of Endodontics 2 (1976): 369-373.

14. Ajeti NN., et al. "The effect of gaseous ozone in infected root canal". Open Access Macedonian Journal of Medical Sciences 6.2 (2018): 389-396.

15. Indurkar MS and Verma R. "Effect of ozonated oil and chlorhexidine gel on plaque induced gingivitis: A randomized control clinical trial". Journal of Indian Society of Pedodontics and Preventive Dentistry 20.1 (2016): 32-35.

\section{Assets from publication with us}

- Prompt Acknowledgement after receiving the article

- Thorough Double blinded peer review

- Rapid Publication

- Issue of Publication Certificate

- High visibility of your Published work

Website: $\underline{w w w}$.actascientific.com/

Submit Article: www.actascientific.com/submission.php

Email us: editor@actascientific.com

Contact us: +919182824667 